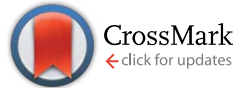

Cite this: RSC Adv., 2015, 5, 41795

Received 16th February 2015

Accepted 22nd April 2015

DOI: $10.1039 / \mathrm{c} 5 \mathrm{ra07039b}$

www.rsc.org/advances

\section{Zwitterionic carbene adducts and their carbene isomerst:}

\begin{abstract}
Z. Kelemen, ${ }^{a}$ R. Streubel ${ }^{b}$ and L. Nyulászi ${ }^{\star a}$
$\mathrm{N}$-heterocyclic carbenes ( $\mathrm{NHC}$ ) and abnormal NHCs (aNHC) form the stable adducts, 1 and 2, with X $\left(\mathrm{CH}_{2}\right.$, $\mathrm{SiH}_{2}, \mathrm{NH}, \mathrm{PH}, \mathrm{O}, \mathrm{S}$ ). This series of compounds has been investigated computationally, together with their $\mathrm{H}$ shifted isomers, 3 and 4, which are substituted aNHC and NHC, respectively. The relative stability of the (substituted) abnormal carbenes (3) with respect to 4 does not depend on the type of substituent. The stability of the betaine forms, 1 and 2 (with respect to 4), is related to the electronegativity of the heteroatom in X, however the second and third row heteroatoms exert different effects on stabilization. NRT analysis revealed that for 1 and 2, the double bonded contributions are higher for the second than for the third row elements, which, however, have larger ionic contributions, in agreement with their large $\mathrm{p}_{z}$ orbital contribution in the $\pi$-type HOMO. The Si compounds exhibit trans-bent structures in their formal double bond with large s-orbital contribution, and are consequently highly ylidic. In the case of nitrogen and phosphorus compounds, the energies of the two $\mathrm{H}$-shifted forms (2 and 4 ) are close to each other, giving rise to a possible tautomeric equilibrium, which can be fine-tuned by proper substituents. While for the NHCs (3) and aNHCs (4), significant NICS aromaticity was obtained, the zwitterionic compounds ( 1 and 2 ), in particular those with second row substituents having a high double bond character, exhibit a reduced aromaticity.
\end{abstract}

\section{Introduction}

Recently, several N-heterocyclic carbene ( $\mathrm{NHC})^{1}$ based ylidic, and abnormal NHC (aNHC) $)^{2}$ based mesoionic compounds ${ }^{3}$ (dipolar compounds, which cannot be represented by a single Lewis-structure) were synthesized. ${ }^{4-13}$ All of them can be considered as adducts between an NHC (or aNHC) and a subvalent compound (carbene, silylene, nitrene and phosphinidene) (Fig. 1). Among the carbene adducts, the named Breslowintermediate $^{14}$ (Fig. 1: $1 \mathrm{X}$ : $\mathrm{CROH}$ ), an Umpolung catalyst, ${ }^{15}$ which can be considered as an NHC-hydroxycarbene adduct, is of specific importance. ${ }^{16}$ Despite the necessity to involve $1 \mathrm{X}$ : $\mathrm{CPhOH}$ in the benzoin condensation, a synthetically valuable $\mathrm{C}-\mathrm{C}$ bond formation reaction ${ }^{17}$ was suggested more than 50 years ago, only the saturated analogue, but not the parent compound itself was reported. ${ }^{4}$ The lack of synthetic success can be explained by the relatively high stability of the hydroxycarbenes (Ph-C(:)-OH), destabilizing the double bond ${ }^{18}$ of $\mathbf{1}$, which is linking the two carbene units of the adduct. In

${ }^{a}$ Department of Inorganic and Analytical Chemistry, Budapest University of Technology and Economics, Szt Gellért tér 4 H-1111, Budapest, Hungary.E-mail: nyulaszi@mail. bme. $h u$

${ }^{b}$ Institut fur Anorganische Chemie der, Rheinischen Friedrich-Wilhelms-Universitat Bonn, Gerhard-Domagk-Strasse 1, 53121 Bonn, Germany

$\dagger$ Dedicated to Prof. Manfred Scheer on the occasion of his 60th birthday.

\$ Electronic supplementary information (ESI) available. See DOI: $10.1039 / \mathrm{c} 5 \mathrm{ra} 07039 \mathrm{~b}$ accordance, compounds that can be considered as NHC adducts of the unstable (alkyl or aryl) carbene, are known as deoxy-Breslow intermediates $\left(\mathbf{1} \mathrm{X}: \mathrm{CR}_{2}\right)$.<smiles>[Y]C1=CN([R])CN1[R]</smiles>

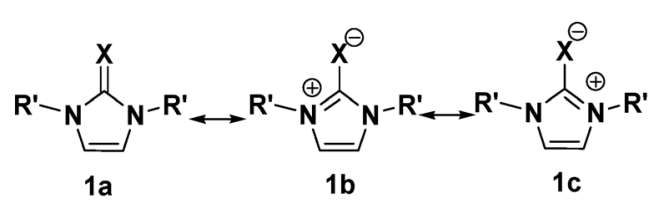

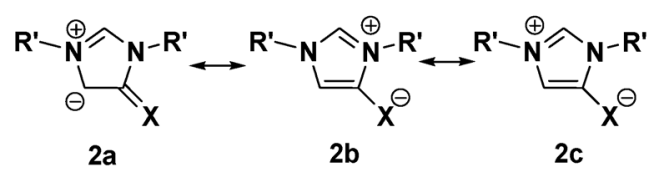

Fig. 11 and 2 as possible NHC and aNHC adducts and their resonance structures. 
This type of compound has indeed higher stability, and was detectable by ESI-MS; ${ }^{19}$ furthermore, compounds with these structural motifs are synthesizable. ${ }^{5}$ Interestingly, the deoxyBreslow intermediate $\left(\mathbf{1} \mathrm{X}: \mathrm{CR}_{2}\right)$ plays an important role in the Umpolung of the $\beta$-position of Michael acceptors. ${ }^{\mathbf{2 0}}$

Apparently, the substitution of the negatively polarized carbon by heteroelements also allows for Umpolung; however, these compounds are termed as inversely polarized, ${ }^{21}$ and the series 1 (X: $\mathrm{CH}_{2}, \mathrm{SiH}_{2}, \mathrm{NH}, \mathrm{PH}, \mathrm{O}, \mathrm{S}$ ) was investigated computationally. ${ }^{22}$ Among the electropositive heteroatoms, the silicon compound $1 \mathrm{X}$ : $\mathrm{SiR}_{2}$ has been described as a silylene adduct (Fig. $1 \mathrm{1b}$ and $1 \mathrm{c} \mathrm{X}: \mathrm{SiR}_{2}$ ) and not as a polarized double bond (1a $\left.\mathrm{X}: \mathrm{SiR}_{2}\right) ;{ }^{6}$ for the phosphorus compound 1 (X: PR), ${ }^{7}$ the term inverse polarization was used. ${ }^{21}$ Most notably, as a chemical consequence of the polarity inversion, complexation by two (!) borane units at phosphorus has been reported. ${ }^{7 a}$ Among the electronegative heteroatoms, 1 (X: NR), ${ }^{8}$ in accordance with the electron excess at the exocyclic nitrogen, was described as a superbase, ${ }^{8 c}$ and oxygen ${ }^{9}$ and sulfur $^{10}$ compounds are also known.

Compound 2, the isomer of $\mathbf{1}$, can be described as an aNHC ${ }^{13}$ adduct of the subvalent species, and compounds of this type are also known. For example, the NHC-silylene adduct $1 \mathrm{X}: \mathrm{SiR}_{2}$ was easily converted to the aNHC-silylene adduct $\left(2 \mathrm{X}: \mathrm{SiR}_{2}\right)$ in a ligand-substitution reaction, ${ }^{6 \boldsymbol{b}}$ and the oxygen analogue $2 \mathrm{X}$ : O, when treated with a strong base gives the corresponding anionic carbene. ${ }^{\mathbf{1 0 , 1 1}}$ The formation of the anionic carbene indicates that for a proper understanding of the two isomeric systems (1 and 2), their possible tautomeric forms (3 and 4 Fig. 2) should also be considered. Indeed, for the nitrogen analogue, the interesting zwitterion-carbene tautomeric equilibrium (system B in Fig. 2) was studied. ${ }^{\mathbf{1 2}}$ DFT calculations showed that the energy difference between the two tautomeric forms is small $\left(\Delta G=5.7 \mathrm{kcal} \mathrm{mol}^{-1}\right.$ at the BP86/def2-SVP level of theory $)^{12 c}$ and the carbene form could be trapped as a transition-metal complex. ${ }^{12 b, c}$ Moreover, in the case of $\mathrm{X}: \mathrm{N}-{ }^{t} \mathrm{Bu}$, the carbene form was detected by NMR spectroscopy (Fig. 2 system B, X: NR), showing that by variation of the substituents, the relative stability of the structures can be tuned. ${ }^{12 a}$ Recently, we reported the phosphorus analogue $2 \mathrm{a}(\mathrm{X}: \mathrm{P}-\mathrm{Ph})$ and showed that the B3LYP/6-311+G** energy difference between the zwitterionic form (2a, X: $\mathrm{P}-\mathrm{Ph})$ and the corresponding $\mathrm{H}$-shift tautomer carbene is only $0.9 \mathrm{kcal} \mathrm{mol}^{-1}$, indicating again the possibility of tautomerization. ${ }^{\mathbf{1 3}}$ Furthermore, zwitterion (also called mesomeric betaine), carbene interconversions were reported recently. ${ }^{23}$

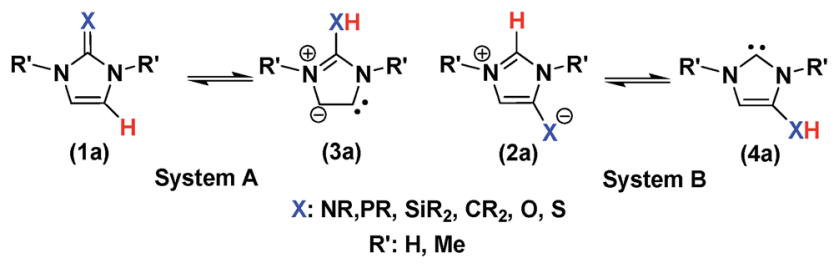

Fig. 2 The investigated tautomeric systems.
The aim of the present study is a comprehensive computational investigation of the electronic structure of the hetero analogues of the deoxi Breslow-intermediate 1 with their "abnormal" isomers 2, including stability, electronic structure, aromaticity, and reactivity indices. For a more complete understanding, carbenes $\mathbf{3}$ and $\mathbf{4}$, which are involved in the tautomeric equilibria with the zwitterionic forms $\mathbf{1}$ and $\mathbf{2}$ (systems A and B in Fig. 2), will also be considered.

\section{Methods}

All calculations have been carried out with the Gaussian 09 program package. ${ }^{24}$ Full geometry optimization was performed for all the molecules at the B3LYP/6-311+G**, B3LYP/cc-pvTZ, $\omega-\mathrm{B} 97 \mathrm{XD} / 6-311+\mathrm{G}^{* *}$, and $\mathrm{M} 06-2 \mathrm{X} / 6-311+\mathrm{G}^{* *}$ levels, and for the optimized structures, the Hessian was calculated to check that a real minimum was obtained. For smaller systems, MP2/6$311+\mathrm{G}^{* *}$ calculations were also carried out. For a better understanding of the electronic structure, we calculated NICS as an aromaticity measure ${ }^{25}$ and carried out NRT studies. ${ }^{26}$ In order to gain a deeper insight into the factors determining the reactivity of the investigated compounds, conceptual DFT indices, ${ }^{27}$ originating from the ground state electron density of the molecules were also calculated, to estimate their electrophilic and nucleophilic characters.

\section{Results and discussion}

Firstly, the thermodynamic stability has been evaluated for species 1-4 with a $\mathrm{R}^{\prime}$ : Me and $\mathrm{R}^{\prime}$ : $\mathrm{H}$ substituent at the B3LYP/6$311+\mathrm{G}^{* *}$ level (and $\mathrm{R}^{\prime}$ : $\mathrm{H}$ substituent at the B3LYP/cc-pvTZ, $\omega \mathrm{B} 97 \mathrm{XD} / 6-311+\mathrm{G}^{* *}$ and $\mathrm{M} 06-2 \mathrm{X} / 6-311+\mathrm{G}^{* *}$ data are compiled in Tables S1-S4 in the ESI -all giving similar results). The energy difference between the normal (4) and the abnormal carbenes (3) is between 16.0 and $19.8 \mathrm{kcal} \mathrm{mol}^{-1}$ (Fig. 3) at the B3LYP/6-311 $+\mathrm{G}^{* *}$ level of theory throughout the investigated series. These values are close to the $16.3 \mathrm{kcal} \mathrm{mol}^{-1}$ energy difference between the parent $\mathrm{NHC}$ and the aNHC, ${ }^{\mathbf{1 3}, 28}$ indicating that the substituent effect on the five-membered ring is not position-sensitive. It can be noted that this behavior depends on the substituent; moreover, the energy difference

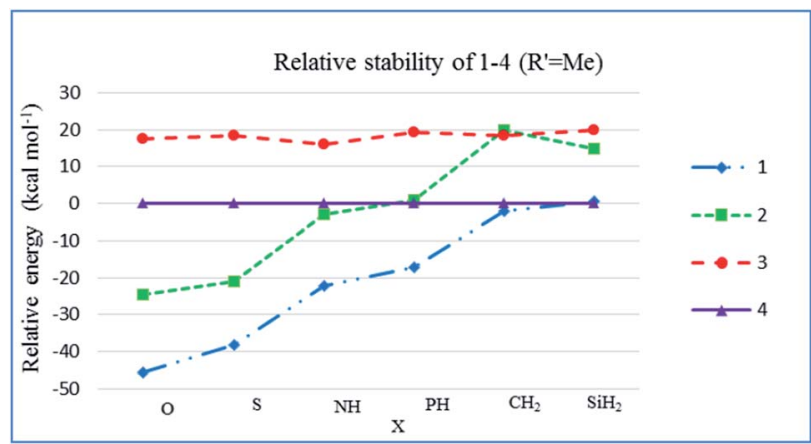

Fig. 3 Relative stability of $1-4\left(\mathrm{R}^{\prime}: \mathrm{Me}\right)$ at B3LYP/6-311+G** level. The substituted NHC 4 was set as reference energy. 
between the NHC and the aNHC adducts of $\mathrm{CO}_{2}$ amounts to only $10 \mathrm{kcal} \mathrm{mol}{ }^{-1} \cdot{ }^{28}$ The relative stability of the zwitterionic forms 1 and 2 (with respect to 4), however, depends strongly on the type of the heteroatom (Fig. 3). Clearly, the zwitterions are stabilized by the electronegative heteroatoms, apparently preferring the occupation of the negatively charged position (for the calculated atomic charges see Tables S5-S7 of the ESI+) of the zwitterionic structure. Compound 2 (the aNHC adductFig. 1) is less stable than $\mathbf{1}$ (the NHC adduct-Fig. 1) by about 20 $\mathrm{kcal} \mathrm{mol}^{-1}$ : moreover, this value is close to the energy difference between the parent aNHC and NHC. Considering the zwitterionic structures as carbene (NHC or aNHC) adducts with the hetero-carbene analogue X (Fig. 1), this behavior shows that the stability of the carbene unit is linearly related to the stability of the "double" bond formed. Likewise, we have previously shown an excellent linear correlation between the stabilization of carbenes and the stability of their (double bonded) dimers. ${ }^{18}$ It can be noted that the energy difference between the two zwitterionic isomers (1 and 2) is slightly higher (19-22 kcal mol$\left.{ }^{-1}\right)$ in the case of the second row elements $(\mathrm{C}, \mathrm{N}, \mathrm{O})$ than for the third row elements (14-18 kcal mol $\left.{ }^{-1}\right)$. Altogether, the most stable of the four isomers is the $\mathbf{1}$ zwitterionic form, although its energetic preference decreases from the most electronegative oxygen in the order $\mathrm{O}>\mathrm{S}>\mathrm{N}>\mathrm{P}>\mathrm{C}>\mathrm{Si}$ (Fig. 3), and for the most electropositive $\mathrm{Si}$ compound, $\mathbf{4}$ is slightly more stable than $\mathbf{1}\left(\mathbf{4} \mathrm{R}^{\prime}: \mathrm{H}\right.$ is also more stable than 1 for $\mathrm{X}: \mathrm{CH}_{2}$ at $\omega$-B97XD/6-311+G** and M06-2X/6-311+G**-see Tables S3 and S4 $\$$ ). In order to see whether or how the relative stabilities of the four isomeric structures depend on the choice of the $\mathrm{NHC}$, the relative stabilities of the analogous thiazol-adducts were also calculated, exhibiting a similar relative stability pattern (Table S8 in the ESI

From Fig. 3, it can be clearly seen that the energy difference between zwitterion (1) and its $\mathrm{H}$-shifted possible tautomer aNHC (3) is quite large for all the heteroatoms (19.2-63.2 kcal $\mathrm{mol}^{-1}$ at B3LYP/6-311+G**). Thus, in the tautomeric system $\mathbf{A}$ (Fig. 2), only 1 can be observed even if we consider that substituents might exert some energetic effect. For the tautomeric system B (Fig. 2), the situation is more complex. While the NHC form (4) is more stable than the zwitterionic 2 in the case of $\mathrm{Si}$ and $\mathrm{C}$, for heteroatoms $\mathrm{O}$ and $\mathrm{S}$, the stability ordering is reversed, in accordance with the generally known lower stability of the enol form. For the $\mathrm{N}$ and $\mathrm{P}$ analogues, the energies of the two $\mathrm{H}$-shifted forms are close to each other (in agreement with the earlier reports ${ }^{12}$ ), giving rise to a possible tautomeric equilibrium.

For a better understanding of the energy difference between $\mathbf{1}$ and 4, we decided to investigate the electronic structure of these compounds in more detail. Firstly, natural resonance theory analysis (NRT) was applied for 1-4 $\left(\mathrm{R}^{\prime}: \mathrm{H}\right)$ to estimate the weight $^{29}$ of the possible resonance structures, including the ylidic contributions (using $\mathrm{R}^{\prime}$ : $\mathrm{H}$, the number of low weight resonance structures is reduced, while the main conclusions remain unaltered). While for $\mathbf{4}$, the two leading resonance structures $^{29}$ have a large weight $(32.5-37.0 \%$, Table S9 in the ESI $\$$ ), for the abnormal carbenes 3, more resonance structures contribute (Table S10 in the ESIt) due to the lower local
Table 1 The sum of the weight of the single and the double bond containing B3LYP/6-311+G** resonance structures of 1 and 2 . For the summation, the most important leading resonance structures ${ }^{29}$ were used, see in ESI

Sum of the weight of the leading resonance structures as \%

Bond between the imidazolium

ring and the heteroatom

$\begin{array}{llllll}\mathrm{O} & \mathrm{S} & \mathrm{N} & \mathrm{P} & \mathrm{C} & \mathrm{Si}\end{array}$

1 Double bonded Single bonded ylidic

2 Double bonded Single bonded ylidic

$\begin{array}{llllll}62.8 & 37.7 & 67.6 & 39.9 & 72.4 & 15.1\end{array}$

$\begin{array}{llllll}22.8 & 41.4 & 20.4 & 36.7 & 16.8 & 54.8\end{array}$

$\begin{array}{llllll}43.7 & 28.2 & 41.3 & 24.7 & 34.9 & 12.0\end{array}$

$\begin{array}{llllll}28.3 & 30.0 & 17.5 & 20.4 & 11.7 & 62.2\end{array}$

symmetry of the $\pi$-system. The similar contribution of the resonance structures indicates a rather even electron distribution.

In the case of $\mathbf{1}$, the weight of the double-bond-containing structures is large for the second row elements, i.e. $\mathrm{C}, \mathrm{N}, \mathrm{O}$ : $62.8-72.4 \%$ (Table 1), and is reduced for $\mathrm{S}$ and $\mathrm{P}$ (37.7 and $39.9 \%)$; moreover, the silicon compound exhibits a much lower (15.1\%) value (the leading structures with their weight are given in Tables S11 and S12 in the ESI $\$$ ). The investigation of the different covalent bond orders (Mayer, ${ }^{30}$ Wiberg, ${ }^{31}$ Gordy $^{32}$ and natural bond order ${ }^{26}$ - Table S13 in the ESI $\$$ ) allows for a similar conclusion. Although the numerical values differ, the preference for double bond formation by the lighter elements can clearly be seen. Moreover, these data are in accordance with the results of Frison and Sevin, ${ }^{22}$ who analysed the back-bonding from $\mathrm{X}$ towards the NHC unit using Charge-Decomposition Analysis (CDA), obtaining by far the smallest value for the back bonding in the case of the Si compound.

It can be noted that the "double bond energy" estimations for the $\mathrm{C}=\mathrm{X}$ bonds gave similar tendencies. For the second row elements $\mathrm{C}, \mathrm{N}$ and $\mathrm{O}, 70$ to $93 \mathrm{kcal} \mathrm{mol}^{-1}$ values were reported, ${ }^{33}$ while the third row $\mathrm{P}$ and S-containing compounds exhibit somewhat reduced values (49 and $55 \mathrm{kcal} \mathrm{mol}^{-1}$, respectively), and the $\mathrm{C}=$ Si double bond has by far the lowest $\left(36 \mathrm{kcal} \mathrm{mol}^{-1}\right)$ double bond energy. ${ }^{33}$ To describe the bonding situation in $\mathbf{1}$, the zwitterionic structures, with the negative charge at the heteroatom $\mathrm{X}$, have a significant weight, which increases together with the electronegativity within the series containing second row elements. For the sulfur-phosphorus-silicon series, the contribution of these resonance structures is significantly larger, in accordance with their lower double bond character.

The case of the silicon compound is specific within this series. Due to the reduced isovalent hybridization of the third row elements, ${ }^{34}$ the formation of the classical double-bonded structure (but not the ylide formation with an s-type lone pair) is hindered, as can also be seen from the trans-bent geometry of $1 \mathrm{X}: \mathrm{SiH}_{2}$ (for a discussion of the trans-bent structures in the case of $\mathrm{Si}=\mathrm{Si}$ and related bonds, see the works of Trinquier). ${ }^{35}$ In this respect, $2 \mathrm{X}$ : $\mathrm{Si}$ is also non-planar, while all other molecules among the series of the zwitterionic series (1 and 2) have $C_{\mathrm{s}}$ symmetry.

The shape of the HOMO in the case of 1 (Fig. 4) and 2 (Fig. S1 in the ESI sheds further light on the different behaviors of the 

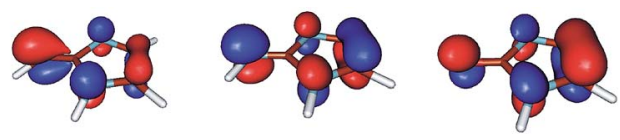

$1 \mathrm{X}=\mathrm{CH}_{2}$

A

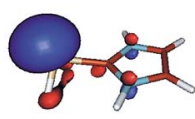

$1 \mathrm{X}=\mathrm{SiH}_{2}$ D

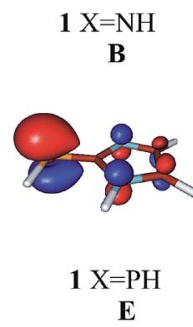

$\mathbf{E}$

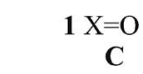

C

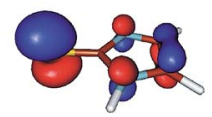

$1 \mathrm{X}=\mathrm{S}$
Fig. $4 \mathrm{HOMO}$ of $1\left(\mathrm{R}^{\prime}\right.$ : H) with different $\mathrm{X}$ heteroatoms.

second and third row elements. The contribution of the heteroatom to the HOMO is significantly smaller for the second row elements (A-C) than for their third row counterparts (D-F). Furthermore, as discussed above in the case of Si (D), the interaction with the ring $\pi$-orbital is nearly negligible, in accordance with the significant "s" character of the Si orbital. A further noteworthy feature is that in the case of the carbon and the phosphorus compounds, the orbital at the heteroatom is significantly polarized toward the $\pi$-system of the ring, while for the other compounds, this effect is much smaller. In this respect, it can also be noted that the conjugative ability of the $\mathrm{P}=\mathrm{C}$ double bonds was shown to be similar to that of the $\mathrm{C}=\mathrm{C}$ bonds ${ }^{36}$ as an apparent consequence of the nearly matching ionization energies of the corresponding p orbitals of $\mathrm{CH}_{3}$ (ref. 37) and $\mathrm{PH}_{2},{ }^{38}$ as is discussed subsequently. ${ }^{39}$ The HOMOs in the series of 2 (Fig. $\mathrm{S} 1$ in the ESI ) show similar behavior to the HOMOs in 1.

Altogether, for the second row heteroatoms, the leading resonance structures ${ }^{29}$ contribute by more than $80 \%$ to the total; for the third row heteroatoms, their contribution is between $70 \%$ and $80 \%$. In the case of the mesoionic 2 , the trends are similar, although the contribution from the double bonded structures and also the sum of the weight for the leading resonance structures ${ }^{29}$ is $10-20 \%$ less than in the case of $\mathbf{1}$ (Table 1 ).
Clearly, to describe the "non-conventional" bonding by "conventional" resonance structures, more structures should be considered.

The structures with dominant exocyclic double bond contributions should exhibit a small cyclic delocalization. Thus, we decided to investigate the aromaticity in the imidazole rings, considering the NICS $(0)^{25 a}$ and $\operatorname{NICS}(1)^{25 b}$ aromaticity measures for $1,2,3$, and 4 (Table 2). The NICS values of the carbene forms (3 and 4) indicate significant aromatic character, ${ }^{\mathbf{4 0}}$ in accordance with the balanced weight of the different resonance structures, as was noted above. It can also be concluded that the effect of the substituents on the $\pi$-system is minor. It can especially be noted that the aromaticity of aNHCs is similar to that of NHCs, ${ }^{41}$ showing that despite the "strange mesoionic" bonding, the delocalization in the $\pi$-system itself is only slightly affected by the position of the dicoordinated carbon.

However, the aromaticity of the zwitterionic forms ( 1 and 2$)$ is in most cases (except for the NICS(0) value for $1 \mathrm{X}$ : $\mathrm{SiH}_{2}-$ see below) significantly smaller than that of their carbene isomers, as was noted before in the case of $\mathbf{1}$ type compounds (although our ordering within the series differs somewhat from that reported before). ${ }^{22}$ The aromaticity is especially low in the case of the deoxy-Breslow intermediate $1 \mathrm{X}: \mathrm{CH}_{2},{ }^{4 j, k, 33,42}$ which is in agreement with the significant exocyclic double bond character discussed above. The reduced aromaticity is also indicated by the slightly pyramidal nitrogens in the imidazolium ring. As expected, the silicon analogue, $1 \mathrm{X}$ : $\mathrm{SiH}_{2}$, which exhibits the largest contributions from the ylidic resonance structures in the NRT analysis, exhibits the largest aromaticity in agreement with the earlier results. ${ }^{22}$ It can be noted that the NICS(1) values are in each case larger for the third row elements than for their second row counterparts. This increased aromaticity indicates increased stabilization, and this is in accordance with the relative energies shown in Fig. 3, wherein the third row elements always exhibit larger relative stabilities than their diagonally-related second row counterparts ( $\mathrm{N}-\mathrm{S}$ and $\mathrm{C}-\mathrm{P})$ with similar electronegativity. While the NICS values do not differ significantly between the $\mathbf{1}$ and $\mathbf{2}$ series, it is noteworthy that for 2 (X: $\mathrm{O}, \mathrm{S}$ and $\mathrm{NH}$ ), significantly larger NICS values than ours were reported, although no unit was given. ${ }^{43}$ Moreover, in the aNHC adduct 2 series, the most aromatic silyl compound is even more aromatic, while the least

Table 2 NICS(0), NICS(1) in ppm, electrophilicity ( $\omega$ in au) and nucleophilicity ( $N$ in au) of the investigated compounds 1-4

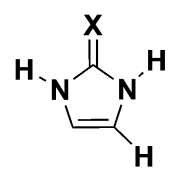

1

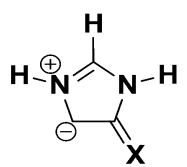

2

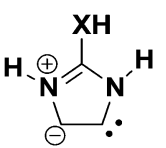

3

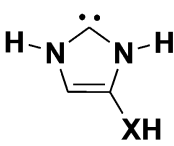

4

\begin{tabular}{|c|c|c|c|c|c|c|c|c|c|c|c|c|c|c|c|c|}
\hline $\mathrm{X}$ & $\operatorname{NICS}(0)$ & $\operatorname{NICS}(1)$ & $\omega$ & $N$ & $\operatorname{NICS}(0)$ & $\operatorname{NICS}(1)$ & $\omega$ & $N$ & $\operatorname{NICS}(0)$ & $\operatorname{NICS}(1)$ & $\omega$ & $N$ & $\operatorname{NICS}(0)$ & $\operatorname{NICS}(1)$ & $\omega$ & $N$ \\
\hline $\mathrm{O}$ & -10.1 & -4.9 & 0.0594 & 0.0546 & -11.1 & -5.9 & 0.0713 & 0.0815 & -11.9 & -8.3 & 0.0862 & 0.0780 & -12.4 & -8.6 & 0.0720 & 0.0466 \\
\hline $\mathrm{S}$ & -9.8 & -6.0 & 0.0633 & 0.0674 & -10.0 & -6.2 & 0.0920 & 0.0937 & -12.6 & -10.4 & 0.0984 & 0.0694 & -12.0 & -9.6 & 0.0776 & 0.0408 \\
\hline $\mathrm{NH}$ & -8.8 & -3.8 & 0.0537 & 0.0806 & -9.0 & -4.1 & 0.0591 & 0.1102 & -11.9 & -9.4 & 0.0723 & 0.0817 & -12.0 & -8.8 & 0.0653 & 0.0539 \\
\hline $\mathrm{PH}$ & -8.6 & -4.8 & 0.0567 & 0.1027 & -7.4 & -3.9 & 0.0801 & 0.1283 & -12.7 & -10.5 & 0.0914 & 0.0716 & -11.4 & -8.5 & 0.0738 & 0.0426 \\
\hline $\mathrm{CH}_{2}$ & -6.8 & -2.5 & 0.0423 & 0.1079 & -5.4 & -1.3 & 0.0457 & 0.1408 & -12.4 & -9.9 & 0.0626 & 0.0828 & -11.8 & -9.4 & 0.0580 & 0.0509 \\
\hline $\mathrm{SiH}_{2}$ & -13.5 & -7.3 & 0.0631 & 0.0998 & -11.3 & -8.1 & 0.1060 & 0.1184 & -10.5 & -11.1 & 0.0881 & 0.0724 & -12.2 & -10.1 & 0.0669 & 0.0422 \\
\hline
\end{tabular}


Table 3 The dissociation energy of 1 and 2 in $\mathrm{kcal} \mathrm{mol}^{-1}$ at the B3LYP/ $6-311+G * *$ level of theory. $\mathrm{X}: \mathrm{SiH}_{2}$ has been considered singlet; for the other substituents, triplet ground state was considered

\begin{tabular}{lrr}
\hline & $\Delta E_{\text {dis }}$ & \\
\cline { 2 - 3 } $\mathrm{X}$ & \multicolumn{1}{c}{$\mathbf{1}^{a}$} & \multicolumn{2}{c}{} \\
\hline $\mathrm{CH}_{2}$ & 103.4 & 99.1 \\
$\mathrm{SiH}_{2}$ & 49.8 & 53.3 \\
$\mathrm{NH}$ & 102.6 & 97.0 \\
$\mathrm{PH}$ & 58.9 & 59.2 \\
$\mathrm{O}$ & 139.0 & 135.8 \\
$\mathrm{~S}$ & 87.6 & 88.5 \\
${ }^{a}$ The data agree well with those obtained by Frison and Sevin. ${ }^{22}$ & \\
& &
\end{tabular}

aromatic carbon compound is even less aromatic than their analogues in the $\mathbf{1}$ series.

It is worth investigating the dissociation energy $\left(\Delta E_{\mathrm{dis}}\right)$ of $\mathbf{1}$ and 2 compared to $\mathrm{NHC}+\mathrm{X}$, and aNHC $+\mathrm{X}$, respectively (Table 3 ), in order to see whether or not these zwitterionic compounds might be considered as viable transfer agents for the hypovalent $\mathrm{X}$ unit.

In the dissociation, we considered the $\mathrm{X}$ subvalent fragments in their ground state, which is triplet with the exception of silylene, thus the present data do not give a full account for the dissociation process itself, but rather provide an indication of how feasible the dissociation is. The $\Delta E_{\text {dis }}$ values for the second row elements are between 97.0 and $139.0 \mathrm{kcal} \mathrm{mol}^{-1}$ and for $\mathbf{1}$, this value is somewhat (by 4-5 kcal mol${ }^{-1}$ ) higher than for 2, indicating the formation of a stable adduct. The stability is also large in the case of the sulfur compound (87.6 and $88.5 \mathrm{kcal}$ $\mathrm{mol}^{-1}$ ), while for Si and $\mathrm{P}$, the $\Delta E_{\mathrm{dis}}$ values are between 49.8 and $59.2 \mathrm{kcal} \mathrm{mol}^{-1}$. Considering the entropy contribution, the dissociation is even more favoured in terms of the Gibbs free energy. Thus, it might be possible that stabilized silylenes and phosphinidenes can be transferred, once formed as NHC (or aNHC) adducts, making these zwitterionic compounds highly interesting synthetic intermediates.

Since the chemical behavior of the H-shifted tautomers could be changed dramatically after the $\mathrm{H}$-shift, it is worth investigating their expected reactivity. While in the case of 3 and 4, the divalent carbon centre, which is characterized by an empty 2 p orbital and an in-plane lone pair-like orbital, determines the reactivity of the molecule, in the case of $\mathbf{1}$ and 2 , the partially negative heteroatom should play an important role. Among the two carbenes, 3 type compounds (aNHCs) exhibit an even stronger nucleophilic character $(N=0.0694-0.0828$ a.u. $)$ than 4 type compounds $(N=0.0408-0.0539$ a.u. $)$, which was in full agreement with their increased basicity and also with the stability of their complexes.,22,40f,42,44 The heteroatom substituent has only little effect on the nucleophilicity of the carbene. ${ }^{\mathbf{4 5}}$ The nucleophilicity of the zwitterionic $\mathbf{1}$ and $\mathbf{2}$ is larger than that of the carbenes 3 and 4 . Comparing 1 and 2, the nucleophilic character of the 2-type compounds is higher. Nevertheless, since the HOMO is more localized at the heteroatom in the case of third row $\mathrm{X}$, it is expected that these compounds will react with electrophiles with the highest selectivity at the heteroatom.

Since the energy difference between the zwitterionic and the carbene form is small in the case of $\mathrm{P}^{\mathbf{1 3}}$ and $\mathrm{N}^{\mathbf{1 2}}$ and the substituents on the phosphorus or on the imidazolium ring have some apparent effect on the relative stability of these compounds, we examined the effects of substituents at $\mathrm{P}$ and $\mathrm{N}$. We considered substituents with different electronic and steric properties (methyl, tert-butyl, trifluoromethyl, fluoro, chloro and phenyl-Table 4). While the strong electron-withdrawing $\mathrm{CF}_{3}$ group significantly decreases the stability of carbene, the electron donating methyl and tert-butyl group increases the stability of carbene, in good agreement with earlier observations that $4\left(\mathrm{X}: \mathrm{N}-{ }^{t} \mathrm{Bu}\right)$ was indeed observed spectroscopically. ${ }^{12}$ This substituent is likely to stabilize the carbene form $\mathbf{4}$ for the phosphorus derivative, although our calculations predict a slight preference of the carbene $\mathbf{4}$ in the case of the phenyl substituents, wherein experimentally only 2 was observed. ${ }^{13}$

\section{Conclusions}

The computational investigation of the isomeric molecules, 14, with different heteroelements at the exocyclic positions, reveals systematic changes in their electronic structure and consequently in their relative stability, finally giving rise to interesting tautomeric equilibria in the $\mathbf{2 a - 4 a}$ systems with heteroelements phosphorus and nitrogen, expanding the possible reactivity of these compounds. The relative stability of the 1-2 and 3-4 pairs is determined by the stability difference

Table 4 The substituent effect on the relative stability of the carbene form in $\mathrm{kcal} \mathrm{mol}^{-1}$ in system B. Negative values indicate that the carbene form 4 is more stable than 2

\begin{tabular}{|c|c|c|c|c|}
\hline $\mathrm{R}$ & \multicolumn{2}{|c|}{$\Delta E \mathrm{X}: \mathrm{N}\left(\mathrm{kcal} \mathrm{mol}^{-1}\right)$} & \multicolumn{2}{|c|}{$\Delta E \mathrm{X}: \mathrm{P}\left(\mathrm{kcal} \mathrm{mol}^{-1}\right)$} \\
\hline $\mathrm{CF}_{3}$ & 16.0 & 12.7 & 10.7 & 5.6 \\
\hline${ }^{t} \mathrm{Bu}$ & 1.9 & -1.4 & -4.5 & -7.7 \\
\hline $\mathrm{Ph}$ & 6.2 & 2.0 & -0.1 & -3.0 \\
\hline $\mathrm{CH}_{3}$ & 1.9 & 0.0 & -3.1 & -5.0 \\
\hline$\left(\mathrm{CH}_{3}\right)_{3} \mathrm{Si}$ & 4.9 & 1.2 & 2.7 & -0.1 \\
\hline
\end{tabular}


between the NHC and the aNHC, and this ca. $20 \mathrm{kcal} \mathrm{mol}^{-1}$ contribution is nearly unchanged throughout the investigated series. The relative stability of the carbene adduct zwitterions, $\mathbf{1}$ and $\mathbf{2}$, is also related to the electronegativity of the heteroelement; however, the second and third period elements behave differently. Sulfur, phosphorus and especially siliconcontaining systems exhibit significantly lower double bond character and consequently increased charge separation than their second period counterparts. It can be noted that the delocalization within the rings is similar for the NHCs (3) and aNHCs (4), both exhibiting similar NICS values, which are only slightly affected by the substituent on the ring.

\section{Acknowledgements}

Financial support from OTKA K 105417 as well as COST CM 1302 is gratefully acknowledged.

\section{Notes and references}

1 (a) D. Bourissou, O. Guerret, F. P. Gabbai and G. Bertrand, Chem. Rev., 2000, 100, 39-92; (b) D. Enders, O. Niemeier and A. Henseler, Chem. Rev., 2007, 107, 5606-5655; (c) F. E. Hahn and M. C. Jahnke, Angew. Chem., Int. Ed., 2008, 47, 3122-3172; (d) A. J. Arduengo III and G. Bertrand, Chem. Rev., 2009, 109, 3209; (e) J. Vignolle, X. Cattoen and D. Bourissou, Chem. Rev., 2009, 109, 3333; (f) M. Melaimi, M. Soleilhavoup and G. Bertrand, Angew. Chem., Int. Ed., 2010, 49, 8810-8849; $(g)$ T. Droge and F. Glorius, Angew. Chem., Int. Ed., 2010, 49, 6940-6952; (h) D. Martin, M. Melaimi, M. Soleilhavoup and G. Bertrand, Organometallics, 2011, 30, 5304-5313; (i) J. B. Waters and J. M. Goicoechea, Coord. Chem. Rev., 2015, 293-294, 80-94; (j) M. N. Hopkinson, C. Richter, M. Schedler and F. Glorius, Nature, 2014, 510, 485-496.

2 (a) P. L. Arnold and S. Pearson, Coord. Chem. Rev., 2007, 251, 596-609; (b) O. Schuster, L. Yang, H. G. Raubenheimer and M. Albrecht, Chem. Rev., 2009, 109, 3445-3478; (c) S. Gründemann, A. Kovacevic, M. Albrecht, J. Faller and R. H. Crabtree, Chem. Commun., 2001, 2274-2275; (d) E. Aldeco-Perez, A. J. Rosenthal, B. Donnadieu, P. Parameswaran, G. Frenking and G. Bertrand, Science, 2009, 326, 556-557.

3 (a) A. M. Simas, J. Miller and P. A. Filho, Can. J. Chem., 1998, 76, 869-872; (b) A. Schmidt, S. Wiechmann and T. Freese, ARKIVOC, 2013, 424-469.

4 To our best knowledge, there has been no unambiguous identification of the Breslow intermediate itself, although several analogue and derivative was synthesized and characterized: (a) R. Breslow and R. Kim, Tetrahedron Lett., 1994, 35, 699-702; (b) Y.-T. Chen, G. L. Barletta, K. Haghjoo, J. T. Cheng and F. Jordan, J. Org. Chem., 1994, 59, 7714; (c) J. H. Teles, J.-P. Melder, K. Ebel, R. Schneider, E. Gehrer, W. Harder, S. Brode, D. Enders, K. Breuer and G. Raabe, Helv. Chim. Acta, 1996, 79, 61-83; (d) M. J. White and F. J. Leeper, J. Org. Chem., 2001, 66, 5124-5131; (e) W. Schrader, P. P. Handayani, C. Burstein and F. Glorius,
Chem. Commun., 2007, 716-718; (f) H. Rodriguez, G. Gurau, J. D. Holbrey and R. D. Rogers, Chem. Commun., 2011, 47, 3222; $(g)$ The synthesized saturated analogue: A. Berkessel, S. Elfert, V. R. Yatham, J.-M. PNeudörfl, N. E. Schlörer and J. H. Teles, Angew. Chem., 2012, 124, 12537-12541; Angew. Chem., Int. Ed., 2012, 51, 1237012374; (h) D. A. DiRocco, K. M. Oberg and T. Rovis, J. Am. Chem. Soc., 2012, 134, 6143-6145; (i) D. A. DiRocco and T. Rovis, Angew. Chem., 2012, 124, 6006-6008; Angew. Chem., Int. Ed., 2012, 51, 5904-5906; (j) B. Maji, M. Horn and H. Mayr, Angew. Chem., Int. Ed., 2012, 51, 6231-6235; (k) B. Maji and H. Mayr, Angew. Chem., Int. Ed., 2012, 51, 10408-10412; (l) H. Mayr, S. Lakhdar, B. Maji and A. R. Ofial, Beilstein J. Org. Chem., 2012, 8, 1458-1478; (m) C. J. Collett, R. S. Massey, O. R. Maguire, A. S. Batsanov, A. C. O_Donoghue and A. D. Smith, Chem. Sci., 2013, 4, 1514-1522.

5 (a) N. Kuhn, H. Bohnen, J. Kreutzberg, D. Blaserb and R. Boese, Chem. Commun., 1993, 1136; (b) A. J. Arduengo, F. Davidson, H. V. R. Dias, J. R. Goerlich, D. Khasnis, W. J. Marshall and T. K. Prakasha, J. Am. Chem. Soc., 1997, 119, 12742; (c) C. Knappke, J. M. PNeudörfl and A. J. von Wangelin, Org. Biomol. Chem., 2010, 8, 1695-1705; (d) N. Kuhn, M. Göhner and M. Steimann, Z. Naturforsch., B: J. Chem. Sci., 2002, 57, 631.

6 (a) R. S. Ghadwal, H. W. Roesky, S. Merkel, J. Henn and D. Stalke, Angew. Chem., Int. Ed., 2009, 48, 5683-5686; (b) A. P. Singh, P. P. Samuel, K. C. Mondal, H. W. Roesky, N. S. Sidhu and B. Dittrich, Organometallics, 2013, 32, 354357; (c) W. M. Boesveld, B. Gehrhus, P. B. Hitchcock, M. F. Lappert and P. v. R. Schleyer, Chem. Commun., 1999, 755-756.

7 (a) W. J. Marshall and B. Riegel, Inorg. Chem., 1997, 36, 2151; (b) A. J. Arduengo III, H. V. R. Dias and J. C. Calabrese, Chem. Lett., 1997, 143; (c) A. J. Arduengo III, C. J. Carmalt, J. A. C. Clyburne, A. H. Cowley and R. Pyati, Chem. Commun., 1997, 981-982; (d) G. Frison and A. Sevin, J. Organomet. Chem., 2002, 643-644; (e) G. Frison and A. Sevin, J. Phys. Chem. A, 1999, 103, 10998; (f) Y. Wang, Y. Xie, M. Y. Abraham, R. J. Gilliard, P. Wei, H. F. Schaefer III, P. v. R. Schleyer and G. H. Robinson, Organometallics, 2010, 29, 4778-4780; (g) O. Back, M. Henry-Ellinger, C. D. Martin, D. Martin and G. Bertrand, Angew. Chem., Int. Ed., 2013, 52, 2939-2943; (h) A. M. Tondreau, Z. Benkö, J. R. Harmer and H. Grützmacher, Chem. Sci., 2014, 5, 1545-2155.

8 (a) M. Tamm, D. Petrovic, S. Randoll, S. Beer, T. Bannenberg, P. G. Jonesa and J. Grunenberg, Org. Biomol. Chem., 2007, 5, 523; (b) N. Kuhn, R. Fawzi, M. Steimann, J. Wiethoff, D. Bläserb and R. Boese, Z. Naturforsch., B: J. Chem. Sci., 1995, 50, 1779; (c) R. A. Kunetskiy, S. M. Polyakova, J. Vavrik, I. Cisarova, J. Saame, E. Roos Nerut, I. Koppel, I. A. Koppel, A. Kutta, I. Leito and I. M. Lyapkalo, Chem.Eur. J., 2012, 18, 3621-3630.

9 (a) Y. A. Rozin, E. P. Darienko and Z. V. Pushkareva, Chem. Heterocycl. Compd., 1971, 4, 510; (b) C. Glidewell, H. D. Holden and D. C. Liles, J. Mol. Struct., 1980, 66, 325; 
(c) D. Enders, K. Breuer, G. Raabe, J. Runsink, J. H. E. Teles, J. Melder, K. Ebel and S. Brode, Angew. Chem., Int. Ed. Engl., 1995, 34, 1021.

10 (a) G. Ansell, D. M. Forkey and D. W. Moore, Chem. Commun., 1970, 56; (b) G. B. Ansell, J. Chem. Soc., Perkin Trans. 2, 1972, 841; (c) X. L. Tao, M. Le and Y. G. Wang, Synth. Commun., 2007, 37, 399-408.

11 L. I. Kruse, C. Kaiser, W. E. DeWolf, J. A. Finkelstein, J. S. Frazee, E. L. Hilbert, S. T. Ross, K. E. Flaim and J. L. Sawyer, J. Med. Chem., 1990, 33, 781-789.

12 (a) A. A. Danopoulos and P. Braunstein, Chem. Commun., 2014, 50, 3055-3057; (b) A. Danopoulos, K. Y. Monakhov and P. Braunstein, Chem.-Eur. J., 2013, 19, 450-455; (c) A triazole analouge is also known: C. Farber, M. Leibold, C. Bruhn, M. Maurer and U. Siemeling, Chem. Commun., 2012, 48, 227-229; (d) A. Andreas Danopoulos, P. Braunstein, E. Rezabalc and G. Frison, Chem. Commun., 2015, 51, 3049.

13 P. K. Majhi, G. Schnakenburg, Z. Kelemen, L. Nyulászi, D. P. Gates and R. Streubel, Angew. Chem., Int. Ed., 2013, 52, 10080-10083.

14 R. Breslow, J. Am. Chem. Soc., 1958, 80, 3719-3726.

15 X. Bugaut and F. Glorius, Chem. Soc. Rev., 2012, 41, 35113522.

16 O. Hollóczki, Z. Kelemen and L. Nyulászi, J. Org. Chem., 2012, 77, 6014-6022.

17 (a) D. Enders and T. Balensiefer, Acc. Chem. Res., 2004, 37, 534-541; (b) D. Enders, O. Niemeier and A. Henseler, Chem. Rev., 2007, 107, 5606-5655; (c) N. Marion, S. DíezGonzález and S. P. Nolan, Angew. Chem., Int. Ed. Engl., 2007, 46, 2988-3000.

18 L. Nyulászi, T. Veszprémi and A. Forró, Phys. Chem. Chem. Phys., 2000, 2, 3127-3129.

19 S. Matsuoka, Y. Ota, A. Washio, A. Katada, K. Ichioka, K. Takagi and M. Suzuki, Org. Lett., 2011, 14, 3722-3725.

20 (a) C. Fischer, S. W. Smith, D. A. Powell and G. C. Fu, J. Am. Chem. Soc., 2006, 128, 1472-1473; (b) A. T. Biju, M. Padmanaban, N. E. Wurz and F. Glorius, Angew. Chem., 2011, 123, 8562-8565; Angew. Chem., Int. Ed., 2011, 50, 8412-8415.

21 (a) E. Fuchs, H. Heydt, M. Regitz, W. W. Schoeller and T. Busch, Tetrahedron Lett., 1989, 30, 5111-5114; (b) E. Fuchs, B. Breit, H. Heydt, W. Schoeller, T. Busch, C. Krüger, P. Betz and M. Regitz, Chem. Ber., 1991, 124, 2843-2855; (c) A. N. Chernega, A. V. Ruban, V. D. Romanenko, L. N. Markovskii, A. A. Korkin, M. Y. Antipin and Y. T. Struchkov, Heteroat. Chem., 1991, 2, 229-241; (d) L. Weber, Eur. J. Inorg. Chem., 2000, 24252441.

22 G. Frison and A. Sevin, J. Chem. Soc., Perkin Trans. 2, 2002, 1692-1697.

23 M. Liu, M. Nieger and A. Schmidt, Chem. Commun., 2015, 51, 477-479.

24 M. J. Frisch, G. W. Trucks, H. B. Schlegel, G. E. Scuseria, M. A. Robb, J. R. Cheeseman, G. Scalmani, V. Barone, B. Mennucci, G. A. Petersson, H. Nakatsuji, M. Caricato, X. Li, H. P. Hratchian, A. F. Izmaylov, J. Bloino, G. Zheng,
J. L. Sonnenberg, M. Hada, M. Ehara, K. Toyota, R. Fukuda, J. Hasegawa, M. Ishida, T. Nakajima, Y. Honda, O. Kitao, H. Nakai, T. Vreven, J. A. Montgomery Jr, J. E. Peralta, F. Ogliaro, M. Bearpark, J. J. Heyd, E. Brothers, K. N. Kudin, V. N. Staroverov, T. Keith, R. Kobayashi, J. Normand, K. Raghavachari, A. Rendell, J. C. Burant, S. S. Iyengar, J. Tomasi, M. Cossi, N. Rega, J. M. Millam, M. Klene, J. E. Knox, J. B. Cross, V. Bakken, C. Adamo, J. Jaramillo, R. Gomperts, R. E. Stratmann, O. Yazyev, A. J. Austin, R. Cammi, C. Pomelli, J. W. Ochterski, R. L. Martin, K. Morokuma, V. G. Zakrzewski, G. A. Voth, P. Salvador, J. J. Dannenberg, S. Dapprich, A. D. Daniels, O. Farkas, J. B. Foresman, J. V. Ortiz, J. Cioslowski and D. J. Fox, Gaussian 09, Revision B.01, Gaussian, Inc., Wallingford CT, 2010.

25 (a) P. v. R. Schleyer, C. Maerker, A. Dransfeld and N. J. R. van Eikema Hommes, J. Am. Chem. Soc., 1996, 118, 6317-6318; (b) P. v. R. Schleyer, H. Jiao, N. J. R. van Eikema Hommes, V. G. Malkin and O. L. Malkina, J. Am. Chem. Soc., 1997, 119, 12669-12670; (c) H. Fallah-Bagher-Shaidaei, C. S. Wannere, C. Corminboeuf, R. Puchta and P. v. R. Schleyer, Org. Lett., 2006, 8, 863-866; (d) Z. Chen, C. S. Wannere, C. Corminboeuf, R. Puchta and P. v. R. Schleyer, Chem. Rev., 2005, 105, 3842-3888.

26 (a) E. D. Glendening and F. Weinhold, J. Comput. Chem., 1998, 19, 610-627; (b) E. D. Glendening, J. K. Badenhoop and F. Weinhold, J. Comput. Chem., 1998, 19, 628-646.

27 P. Geerlings, F. De Proft and W. Langenaeker, Chem. Rev., 2003, 103, 1793-1874.

28 (a) Z. Kelemen, B. Péter-Szabó, E. Székely, O. Hollóczki, D. Firaha, B. Kirchner, O. Hollóczki, J. Nagy and L. Nyulászi, Chem.-Eur. J., 2014, 20, 13002-13008; (b) D. G. Gusev, Organometallics, 2009, 28, 6458-6461; (c) L. N. Appelhans, D. Zuccaccia, A. Kovacevic, A. R. Chianese, J. R. Miecznikowski, A. Macchioni, E. Clot, O. Eisenstein and R. H. Crabtree, J. Am. Chem. Soc., 2005, 127, 16299-16311.

29 Since NRT analysis give a large number of resonance structures even for $\mathrm{R}^{\prime}$ : $\mathrm{H}$ (for 2 type compounds more than 100), and most of them have a small weight (below $0,5 \%$ ), only the leading structures (with at least $3-5 \%$ weight) were used to determine the sum of the single and double bond containing systems. Accordingly, the sum of the leading structures do not add up to $100 \%$.

30 I. Mayer, J. Comput. Chem., 2007, 28, 204-221.

31 K. B. Wiberg, Tetrahedron, 1968, 24, 1083.

32 W. Gordy, J. Chem. Phys., 1947, 15, 305.

33 P. v. R. Schleyer and D. Kost, J. Am. Chem. Soc., 1988, 110, 2105-2109.

34 W. Kutzelnigg, Angew. Chem., Int. Ed., 1984, 23, 272-295.

35 G. Trinquier and J. Malrieu, J. Am. Chem. Soc., 1987, 109, 5304-5315.

36 L. Nyulászi, T. Veszprémi and J. Réffy, J. Phys. Chem., 1993, 97, 4011-4015.

37 J. A. Blush, P. Chen, R. T. Wiedmann and M. G. White, J. Chem. Phys., 1993, 98, 3557. 
38 J. Berkowitz, L. A. Curtiss, S. T. Gibson, J. P. Greene, G. L. Hillhouse and J. A. Pople, J. Chem. Phys., 1986, 84, 375.

39 Z. Benkő and L. Nyulászi, Top. Heterocycl. Chem., 2009, 19, 27-83.

40 Former studies about the aromatic stabilization of carbenes: (a) O. Hollóczki and L. Nyulászi, J. Org. Chem., 2008, 73, 4794-4799; (b) C. Boehme and G. Frenking, J. Am. Chem. Soc., 1996, 118, 2039-2046; (c) C. Heinemann, T. Müller, Y. Apeloig and H. Schwartz, J. Am. Chem. Soc., 1996, 118, 2023-2038; (d) M.-J. Cheng and C.-H. Hu, Chem. Phys. Lett., 2001, 349, 477-482; (e) S. P. Nolan, Coord. Chem. Rev., 2007, 251, 874-883; $(f)$ A. K. Guha, S. Sarmah and A. K. Phukan, Dalton Trans., 2010, 7374-7383; $(g)$ S. Gronert, J. R. Keeffe and R. A. More O'Ferrall, J. Am. Chem. Soc., 2011, 133, 3381-3389; (h) S. Gronert,
J. R. Keeffe and R. A. More O'Ferrall, J. Am. Chem. Soc., 2011, 133, 11817-11818.

41 R. Tonner, G. Heydenrych and G. Frenking, Chem.-Asian J., 2007, 2, 1555-1567.

42 O. Hollóczki and L. Nyulászi, Org. Biomol. Chem., 2011, 9, 2634-2640.

43 Y. I. Nein and Y. Y. Morzherin, Russ. Chem. Bull., 2012, 61, 1111-1116.

44 H. V. Huynh and G. Frison, J. Org. Chem., 2013, 78, 84858495.

45 (a) A. K. Phukan, A. Kanti Guha, S. Sarmah and R. D. Dewhurst, J. Org. Chem., 2013, 78, 11032-11039; (b) Z. Kelemen, O. Hollóczki, J. Oláh and L. Nyulászi, RSC Adv., 2013, 3, 7970-7978. 